\title{
Extra-anatomic suprahepatic to innominate vein conduit in heterotaxy
}

\author{
Erin A. Paul, MD, ${ }^{\mathrm{a}}$ Alejandro J. Torres, MD, ${ }^{\mathrm{a}}$ Anjali Chelliah, MD, ${ }^{\mathrm{a}}$ Mercedes Martinez, MD, ${ }^{\mathrm{b}}$ \\ Anne M. Ferris, MBBS, ${ }^{a}$ and David M. Kalfa, MD, PhD, ${ }^{c}$ New York, NY
}

\footnotetext{
From the ${ }^{\mathrm{a}}$ Division of Pediatric Cardiology, Department of Pediatrics, ${ }^{\mathrm{b}}$ Division of Gastroenterology, Hepatology and Nutrition, Department of Pediatrics, and ${ }^{\mathrm{c}}$ Section of Congenital and Pediatric Cardiac Surgery, Division of Cardiac, Thoracic and Vascular Surgery, New York-Presbyterian Morgan Stanley Children's Hospital, Columbia University Medical Center, New York, NY.

Disclosures: Authors have nothing to disclose with regard to commercial support.

Received for publication Jan 20, 2018; revisions received March 5, 2018; accepted for publication March 7, 2018; available ahead of print April 12, 2018

Address for reprints: Erin A. Paul, MD, Division of Pediatric Cardiology, New York-Presbyterian Morgan Stanley Children's Hospital, Columbia University Medical Center, 3959 Broadway, CHN 2-253, New York, NY 10032 (E-mail: eas2188@columbia.edu).

J Thorac Cardiovasc Surg 2018;156:327-9

$0022-5223 / \$ 36.00$

Copyright (c) 2018 by The American Association for Thoracic Surgery

https://doi.org/10.1016/j.jtcvs.2018.03.026
}

Video clip is available online.

We present a case of hepatic venous baffle obstruction in left atrial isomerism and dextrocardia in which surgical revision was complicated by atrial size discrepancy and portal hypertension-related varices. A suprahepatic to innominate vein conduit was used to provide hepatic venous egress.

\section{CLINICAL SUMMARY}

A 16-year-old young man with a history of heterotaxy syndrome with left atrial isomerism, dextrocardia, polysplenia, incomplete atrioventricular canal defect, interrupted inferior vena cava with azygous continuation, and anomalous hepatic venous drainage to the left-sided atrium was referred for evaluation. His initial surgical repair at 6 months of age had included ostium primum defect closure, mitral valve cleft repair, and baffling of the hepatic veins to the right-sided atrium. The next year he required resection of a subaortic membrane. His last surgical procedure was at 4 years of age, when he underwent a modified Konno procedure for bilateral outflow tract obstruction and placement of an epicardial pacemaker for sick sinus syndrome.

Several years later, he presented with portal hypertension, biopsy-proven developing cirrhosis, and retroperitoneal, gastrohepatic, paraesophageal, and esophageal varices. Serum testing showed normal transaminase levels, mild and intermittent direct hyperbilirubinemia, and elevated gamma-glutamyl transferase. Echocardiography demonstrated good intracardiac repair, but the anatomy of the hepatic vein baffle could not be visualized. A cardiac

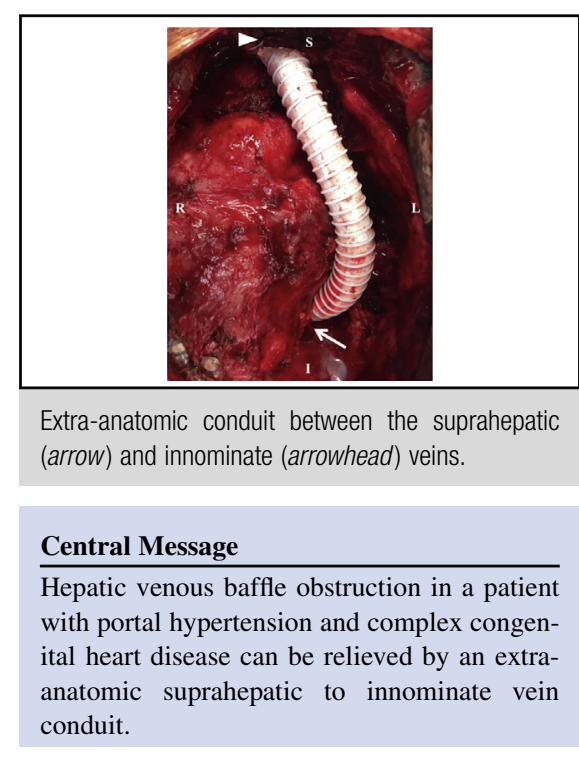

See Editorial Commentary page 330.

computed tomographic angiogram showed complete occlusion of the hepatic veins as they entered the left-sided atrium and intracardiac baffle, a small rightsided atrium, and confirmed the presence of a nodular, cirrhotic liver. Catheterization through transhepatic venous access demonstrated total long-segment occlusion of the hepatic venous baffle between the hepatic vein confluence and the right-sided atrium (Figure 1 and Video 1). Dedicated guidewires and radiofrequency energy were used in an attempt to reopen the baffle but could not be advanced through the fibrotic scar tissue. A multidisciplinary team therefore made a plan to revise the hepatic baffle surgically to relieve the chronic venous obstruction to prevent further progression and promote improvement of his liver disease.

\section{SURGICAL TECHNIQUE}

In this patient with dextrocardia, left atrial isomerism, a rightward and posterior right ventricle, and a leftward and anterior left ventricle (Figure 2), a baffle would ideally connect the suprahepatic venous return with the smaller, posterior, right-sided atrium. The surgery was performed with the patient on cardiopulmonary bypass under hypothermia $\left(28^{\circ} \mathrm{C}\right)$, and a single venous cannula was strategically positioned at the junction of the superior vena cava and azygous continuation. Drop-in suckers 


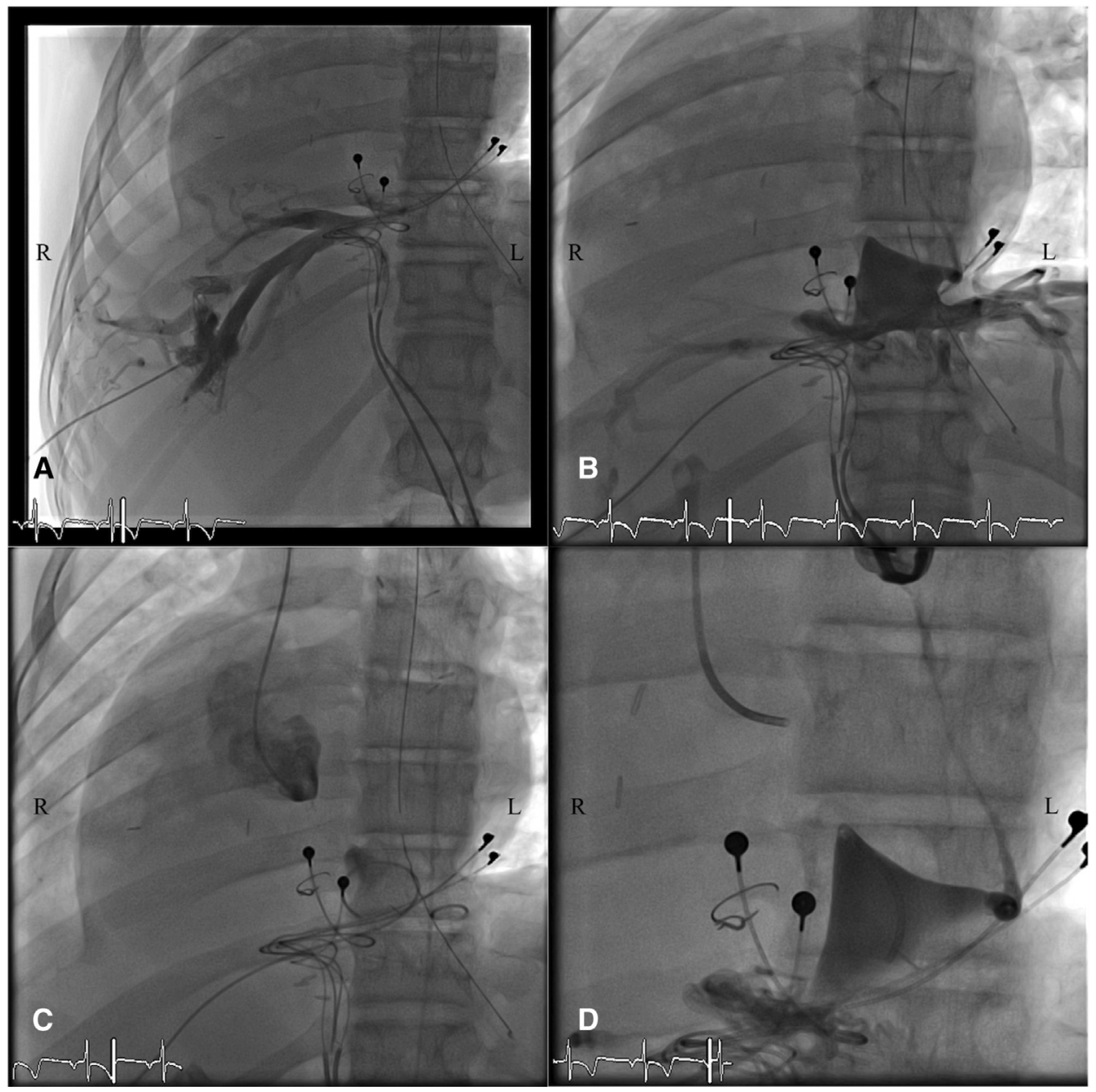

FIGURE 1. Angiography showing the relationship between the posterior right atrium and the hepatic veins. A, Hepatic vein angiogram by transhepatic access shows the lack of egress from the hepatic veins. B, Angiography with the catheter advanced further into the same vessel shows the hepatic venous confluence ending blindly. C, Angiography in the right atrium shows the atrial blind end of the hepatic venous baffle. D, Hepatic vein injection with catheter tips at the blind atrial and hepatic pouches demonstrates the length of the occluded venous baffle. $R$, Right; $L$, left.

\section{Extra-Anatomic Suprahepatic to Innominate Vein} Conduit in Heterotaxy

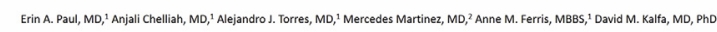

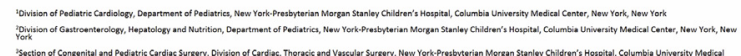

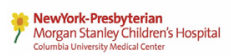

de. Columbia University

VIDEO 1. Angiography shows long-segment hepatic venous baffle obstruction in a 16-year-old young man with a history of left atrial isomerism, dextrocardia, repaired incomplete atrioventricular canal defect, interrupted inferior vena cava with azygous continuation, and anomalous hepatic venous drainage. Computed tomographic imaging demonstrates the smaller, posterior, and rightward atrium. An extra-anatomic suprahepatic to innominate vein conduit was placed to relieve the obstruction. A, Anterior; $L V$, left ventricle; $R V$, right ventricle; $L A$, left atrium; $R$, right; $L$, left; $P$, posterior. Video available at: http://www.jtcvsonline.org/article/S0022-5223(18)30805-5/fulltext. were used to drain the suprahepatic veins. Intraoperative dissection confirmed that the previous hepatic baffle was completely obstructed. The previous baffle was opened, and the suprahepatic vein ostium was located. Nevertheless, given the high risk of recurrent obstruction of an intracardiac hepatic venous baffle because of (1) the acute angle between the suprahepatic venous ostium and the posterior right-sided atrium and (2) the respective locations of the atrioventricular valves and pulmonary veins in the setting of dextrocardia and left isomerism, alternative approaches were considered. Although the azygous vein was the closest systemic vein to the suprahepatic veins according to the computed tomographic scan, an extra-anatomic tube connecting them was not pursued because of the presence of varices in this region. The innominate vein, however, was more accessible. A beveled, 13-mm ringed GORE-TEX (W. L. Gore and Associates, Flagstaff, Ariz) tube was anastomosed lateroterminally to the suprahepatic veins with a running suture (4-0 GORE-TEX suture; W. L. Gore and Associates). The 

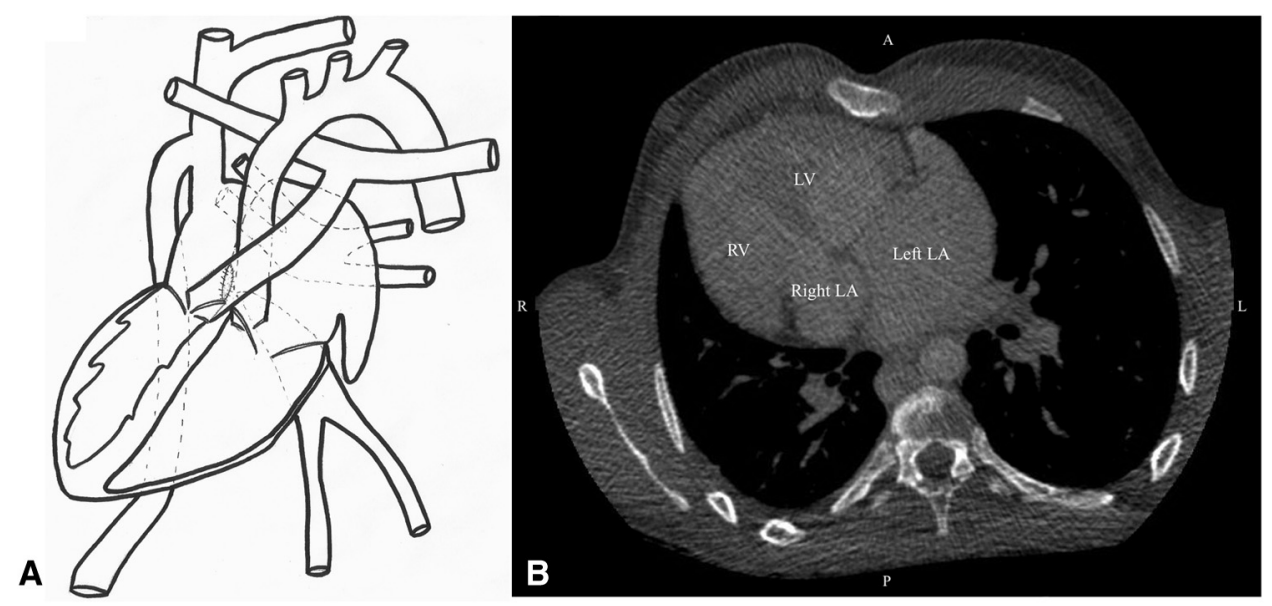

FIGURE 2. A, A schematic diagram of the patient's anatomy. B, Cardiac computed tomographic angiogram in an axial plane showing dextrocardia and the unusual anteroposterior relationships of the atria and ventricles. $A$, Anterior; $L V$, left ventricle; $R V$, right ventricle; $L A$, left atrium; $R$, right; $L$, left; $P$, posterior.

previous connection between the hepatic veins and atria was closed. The distal portion of the tube was also beveled and anastomosed to the innominate vein (5-0 GORE-TEX suture), avoiding any venous or tube distortion or compression (Figure 3). Crossclamp and bypass times were 81 and 103 minutes, respectively.

At 1 postoperative month, the transthoracic echocardiogram showed unobstructed flow from the distal conduit into the

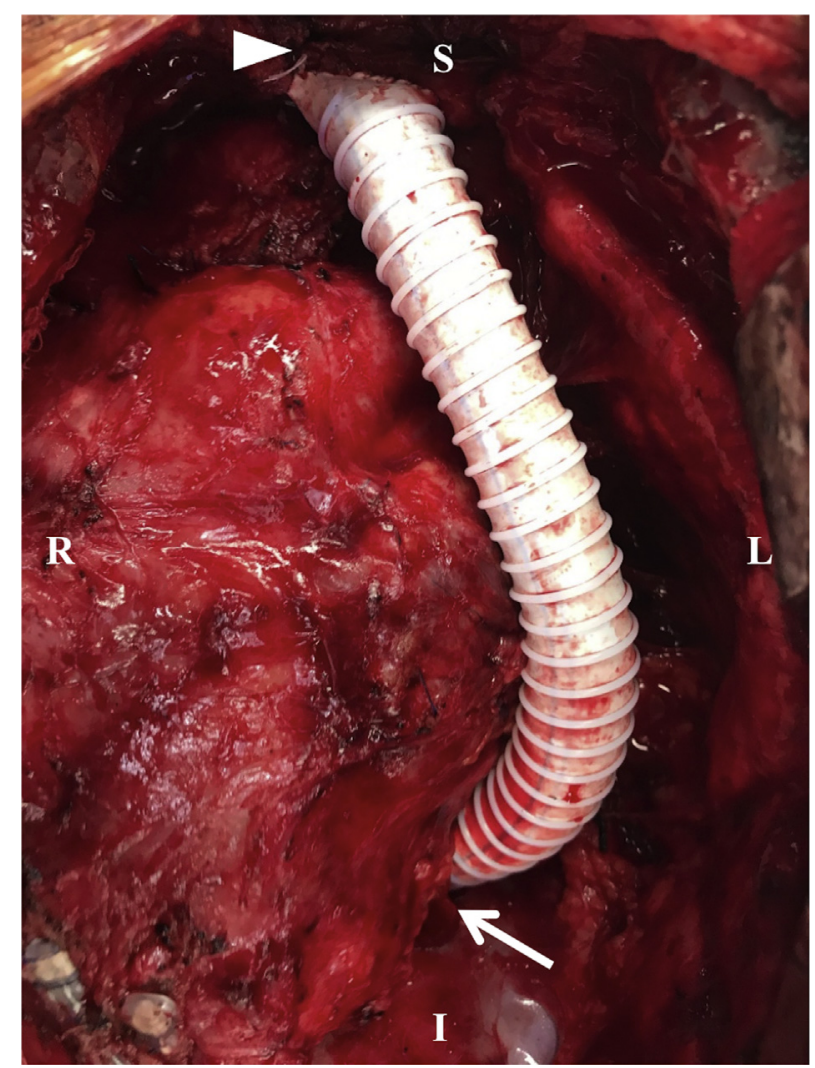

FIGURE 3. Extra-anatomic conduit between the suprahepatic (arrow) and innominate (arrowhead) veins. $R$, Right; $S$, superior; $L$, left; $I$, inferior. innominate vein. The patient's gamma-glutamyltransferase levels had normalized, although his direct bilirubin remained mildly elevated. His liver enzymes remained normal.

\section{DISCUSSION}

Anomalous hepatic drainage may be addressed with direct reanastomosis or intracardiac baffling. In this case of hepatic venous obstruction in left atrial isomerism and dextrocardia, baffle revision was complicated by the spatial relationship between the hepatic and pulmonary veins and atria, as well as by the atrial size discrepancy. Rerouting the hepatic drainage to the azygous vein has been described to address pulmonary arteriovenous malformations in patients with single-ventricle heterotaxy, ${ }^{1,2}$ but it was a less favorable option in this case because it would have required dissection in an area of known varices secondary to portal hypertension. A hepatic to innominate venous conduit has been described in at least 1 case of a patient with heterotaxy and interrupted inferior vena cava who had pulmonary arteriovenous malformations develop after the Fontan procedure. ${ }^{3}$ An extra-anatomic suprahepatic to innominate venous conduit is a novel approach that can provide an excellent postoperative result for children, adolescents, and adults with heterotaxy, interrupted inferior vena cava, and hepatic venous drainage obstruction.

\section{References}

1. Steinberg J, Alfieris GM, Brandt B III, Smith F, Byrum CJ, Fink GW, et al. New approach to the surgical management of pulmonary arteriovenous malformations after cavopulmonary anastomosis. Ann Thorac Surg. 2003;75:1640-2.

2. McElhinney DB, Marx GR, Marshall AC, Mayer JE, del Nido PJ. Cavopulmonary pathway modification in patients with heterotaxy and newly diagnosed or persistent pulmonary arteriovenous malformations after a modified Fontan operation. J Thorac Cardiovasc Surg. 2011;141:1362-70.e1.

3. Wu IH, Nguyen KH. Redirection of hepatic drainage for treatment of pulmonary arteriovenous malformations following the Fontan procedure. Pediatr Cardiol. 2006;27:519-22. 